\title{
PRIVATE SECTOR CONTRIBUTION TO CHILDHOOD IMMUNIZATION: SRI LANKAN EXPERIENCE
}

\author{
S. B. AGAMPODI, D. A. C. L AMARASINGHE*
}

\section{ABSTRACT}

BACKGROUND: The main service provider for childhood immunization in Sri Lanka is the government sector. However, utilization of private sector for childhood immunization is increasing rapidly. Existing national immunization data does not routinely include statistics on private sector immunization delivery adequately. OBJECTIVE: To estimate the proportion of children immunized in the private sector; describe sociodemographic characteristics of private sector users and compare these with government sector users. MATERIALS AND METHODS: A community-based crosssectional descriptive study was conducted using a pre-tested interviewer-administered structured questionnaire. This was done in the Colombo municipal council area using the WHO 30 cluster methodology. The total number of households in the sample was 553. RESULTS: Out of the 5,028 total immunizations reported in the present study, around one-third $(2,544)$ was obtained through the private sector. Nineteen percent (104) of children were exclusively immunized from the private sector. The distribution of usual immunization provider was - government sector $72.3 \%$ (400) and private sector $27.7 \%$ (153). Significant differences were observed $(P<0.001)$ between private and government sector users with regard to family income, social class, ethnicity, religion and educational level of the mother. The age-appropriate immunization among the 12- to 23-month age group was $92.3 \%$ (144) in the government sector, whereas it was $95 \%$ (38) in the private sector. Among the 24- to 35-month age group, it was $91.7 \%$ (121) and $92.7 \%$ (76) respectively. The age-adjusted immunization coverage rates were almost same among the government and private sector users except for the measles vaccine, where the private sector users had significantly $(P=0.016)$ higher coverage. CONCLUSIONS: Utilization of private sector immunization services is high in the Colombo municipal council area.

Key words: Childhood immunization, municipal council area, private sector utilization, usual immunization provider

Provision of immunization services through the private sector has increased globally in

Medical Officer of Health, Beruwala, *Epidemiology Unit, Ministry of Health, Sri Lanka

\section{Correspondence}

Dr. Suneth Buddhika Agampodi, Post Graduate Institute of Medicine, University of Colombo, Sri Lanka.

E-mail: sunethagampodi@yahoo.com recent years. The role of the private sector may be different from country to country as well as within countries.

With the growing demand for immunization, the role of private sector in immunization is showing a consistent increasing trend in 
Sri Lanka. ${ }^{[1]}$ To ensure sustainable high immunization coverage and to achieve future immunization goals, it is very important to integrate the services of the public and private sectors, ${ }^{[2]}$ so that they can complement each other's work in child immunization. However, limited information is available regarding the private sector utilization pattern. Further, the contribution of the private sector in Sri Lankan immunization programs has not been adequately evaluated. ${ }^{[1]}$ The objectives of the present study were to quantify the private sector contribution to immunization coverage and to describe the socio-demographic characteristics of private sector users compared to the government sector users.

\section{MATERIALS AND METHODS}

A cross-sectional descriptive household study was conducted in the Colombo municipal council (CMC) area, which is the administrative and commercial center of the country. It is divided into six districts and 47 wards for administrative purposes. Immunization services are currently provided through the public health department of the CMC and several other service providers. Colombo group hospitals and Colombo south teaching hospital represent the other government sector service providers, whereas private hospitals and general practitioners represent the private sector service providers.

The unit of analysis for this study was a household with at least one child aged between 6 months and 3 years, residing in the $\mathrm{CMC}$ area for at least 6 -months at the time of the field survey. Children whose infant immunization was completed outside the CMC area were excluded from the study even though they were residents of the CMC during the survey.

The modified WHO 30 cluster sampling technique with increased precision was used as the sampling technique. With $95 \%$ confidence limits and 0.1 precision on either side of proportion, the desired sample size amounted to 570. An interviewer-administered structured questionnaire was used to collect the data. Immunization data were extracted from the child health development Record and other immunization cards. For the present study, the age appropriate immunization was determined only for children aged more than 12 months. Children who had received BCG; three doses of each OPV, DTP and Hep B; and one dose of measles by the age of 12 months were considered as immunized up to date. At the age of 24 months, the ageappropriate immunization was defined as receiving $B C G$, four doses of each OPV and DTP, three doses of Hep B and one dose of measles.

Data collection was carried out during July and September 2005. A ward was selected as a single cluster except for two wards with larger population, where two clusters were included in each. Twenty-eight out of 47 wards in the CMC area were selected using probability proportionate to size methodology. The center of the selected ward was the starting point of the data collection process. It was identified using satellite maps available at the Geoinformatics (Pvt.) Limited. A random direction was also determined before visiting the area for each cluster. Trained investigators visited the selected ward, and all the households that met with the inclusion criteria were interviewed. Data collection was done until the required sample size was achieved. This procedure was repeated for all the clusters in the sample.

Ethical clearance was obtained from the Ethical Committee of the Faculty of Medicine, University of Colombo. Informed verbal consent was obtained from the householders before collecting the data.

Coding of data was done manually. Data processing and analysis were carried out using Microsoft Access and SPSS package, Version 13.0. The primary outcome measure was the private sector utilization. Data were analyzed mainly as categorical data. Percentages and contingency table analyses (Chi-square and coefficient of contingency) were the statistical methods used. For comparison of immunization coverage, ageadjusted rates were used (using Government sector users as the reference population) to overcome the age group differences between the government sector and the private sector users in the study sample.

\section{RESULTS}

A total of 3,346 households were visited in the selected 28 wards in the CMC area, of which 570 eligible households were identified. Among 570 eligible households, 553 (97\%) participated in the study while 13 households were unable to participate due to nonavailability of parents or any other person knowledgeable about the child's immunization. Four parents refused to participate.

\section{Private sector utilization}

Private sector (PS) utilization was assessed in three ways. The first measure was the percent of children for whom PS was reported as the child's usual immunization provide (UIP), as perceived by the mother [Table 1] The second measure of PS utilization was to get information on the percent of children fo whom PS was mentioned as the exclusive provider of immunization [Table 2]. Finally, the utilization of PS was analyzed by calculating the number of vaccine doses delivered by the PS providers as a proportion of the total vaccinations delivered. For this purpose, respondents were questioned on each and every single dose of vaccine in order to get the actual provider.

Around $28 \%$ of the respondents indicated the private sector as their child's UIP. Out of this the majority (130) used private hospitals fo

\begin{tabular}{|c|c|c|c|}
\hline $\begin{array}{l}\text { Usual immunization } \\
\text { provider }\end{array}$ & Immunization outlet & N & $\%$ \\
\hline Government sector & $\begin{array}{l}\text { Municipality clinic } \\
\text { Hospital clinic } \\
\text { Sub total }\end{array}$ & $\begin{array}{c}368 \\
32 \\
400\end{array}$ & $\begin{array}{l}66.5 \\
5.8 \\
72.3\end{array}$ \\
\hline Private sector & $\begin{array}{l}\text { Family doctor } \\
\text { Private hospital } \\
\text { Sub total }\end{array}$ & $\begin{array}{l}23 \\
130 \\
153\end{array}$ & $\begin{array}{l}4.2 \\
23.5 \\
27.7\end{array}$ \\
\hline Total & & 553 & 100 \\
\hline
\end{tabular}

Table 2: Distribution of study population by immunization service usage pattern

\begin{tabular}{lcc}
\hline Usage pattern & $N$ & $\%$ \\
\hline Exclusive government sector users (EGS) & 350 & 63.3 \\
Exclusive private sector users (EPS) & 104 & 18.8 \\
Mixed users & 99 & 17.9 \\
Total & 553 & 100
\end{tabular}

Indian J Med Sci, Vol. 61, No. 4, April 2007 
immunization, while only $4.2 \%$ (23) used family physicians as their UIP.

The proportion of children who had been immunized in the private sector at least once during the first three years of life (as either exclusive private sector user or a mixed user) was $36.7 \%$ (203). Out of them, only $18.8 \%$ (104) were exclusive private sector users.

\section{Socio-demographic characteristics of the} study population by UIP groups

Some selected socio-demographic characteristics were explored to understand the differences in PS utilization pattern

[Table 3]. All these variables were determined by directly questioning the respondent except the social class (SC). The latter was derived from the paternal occupation as used by Baker and Hall. It categorizes leading professionals and businessmen as SC-I, lesser professionals and businessmen as SCII, skilled workers as SC-III, semi-skilled workers as SC-IV and unskilled workers as SC-V.

There was a significant difference between government and private sector users with respect to birth order, ethnicity, religion, social class and monthly family income. A significantly higher percentage of first- and

Table 3: Demographic and socioeconomic characteristics of study population according to usual

\begin{tabular}{|c|c|c|c|c|c|c|c|}
\hline \multirow[b]{3}{*}{ Sex } & \multicolumn{7}{|c|}{ Usual immunization provider } \\
\hline & \multicolumn{2}{|c|}{$\begin{array}{c}\text { Government sector } \\
N \%\end{array}$} & \multicolumn{2}{|c|}{$\begin{array}{c}\text { Private sector } \\
N \%\end{array}$} & \multirow[t]{2}{*}{$\begin{array}{c}\text { Total } \\
N\end{array}$} & \multicolumn{2}{|c|}{$\begin{array}{c}\text { Test } \\
\text { Significance } \\
\end{array}$} \\
\hline & & & & & & & \\
\hline \multirow{2}{*}{ Male } & 183 & 70.1 & 78 & 29.9 & 261 & $\chi^{2}=$ & 1.22 \\
\hline & 217 & & 75 & 25.7 & 292 & $\begin{array}{l}\mathrm{df}= \\
P=\end{array}$ & $\begin{array}{c}1 \\
0.27\end{array}$ \\
\hline \multicolumn{8}{|l|}{ Birth order } \\
\hline $1^{\text {st }}$ and $2^{\text {nd }}$ & 289 & 01.1 & 142 & 32.9 & 431 & $\chi^{2}=$ & 27.209 \\
\hline $3^{\text {rd }}$ and above & & 91.0 & 11 & 9.0 & 122 & $\mathrm{df}=$ & 1 \\
\hline \multicolumn{8}{|l|}{ Ethnicity } \\
\hline Sinhalese & 150 & 73.5 & 54 & 26.5 & 204 & $\chi^{2}=$ & 33.399 \\
\hline Tamil & 94 & 58.4 & 67 & 41.6 & 161 & $\mathrm{df}=$ & 3 \\
\hline Muslim & 156 & 83.9 & 30 & 16.1 & 186 & $P<$ & 0.001 \\
\hline Burger ${ }^{*}$ & 0 & 0 & 2 & 100.0 & 0 & & \\
\hline \multicolumn{8}{|l|}{ Religion } \\
\hline Buddhist & 127 & 70.6 & 53 & 29.4 & 180 & $\chi^{2}=$ & 29.118 \\
\hline Hindu & 73 & 57.0 & 55 & 43.0 & 128 & $\mathrm{df}=$ & 4 \\
\hline Islam & 156 & 84.3 & 29 & 15.7 & 185 & $P<$ & 0.001 \\
\hline Roman catholic & 20 & 69.0 & 9 & 31.0 & 29 & & \\
\hline Christian & 24 & 77.4 & 7 & 22.6 & 31 & & \\
\hline \multicolumn{8}{|l|}{ Social class } \\
\hline 1 & 3 & 9.1 & 30 & 90.9 & 33 & $\chi^{2}=$ & 193.67 \\
\hline II & 26 & 33.8 & 51 & 66.2 & 77 & $\mathrm{df}=$ & 4 \\
\hline III & 76 & 61.8 & 47 & 38.2 & 123 & $P<$ & 0.001 \\
\hline IV & 42 & 87.5 & 6 & 12.5 & 48 & $C=$ & 0.51 \\
\hline \multirow{2}{*}{\multicolumn{8}{|c|}{ Monthly family income (Rs.) }} \\
\hline & & & & & & & \\
\hline$<10000$ & 177 & 96.7 & 6 & 3.3 & 183 & $\chi^{2}$ & 200.67 \\
\hline $10001-20000$ & 155 & 86.1 & 25 & 13.9 & 180 & df & 3 \\
\hline $20001-30000$ & 53 & 39.0 & 83 & 61.0 & 136 & $P<$ & 0.001 \\
\hline$>30000$ & 15 & 27.8 & 39 & 72.2 & 54 & $C=$ & 0.52 \\
\hline
\end{tabular}

${ }^{*}$ This category was excluded for the significant testing, $\chi^{2}=$ Chi square, $\mathrm{df}=$ Degree of freedom, $\mathrm{C}=$ Coefficient of contingency second-born children of the family have received vaccines from PS. Even after adjustments for SC and income, this utilization differences according to birth order were significant ( $\mathrm{df}=1, P<0.001)$. PS utilization as the UIP significantly varied in various ethnic groups. Muslim mothers had the lowest preference - of $16.1 \%$ (30) - for PS as their child's UIP. When only the Islam religion was considered, the preference was much lower (15.7\%). Children of Tamil mothers had $41.6 \%$ (67) of PS usage as their UIP; and when mothers belonging to Hindu religion were considered, the utilization increased up to $43 \%$ (55).

PS usage as UIP had a highly significant correlation with the $S C$ distribution $(C=0.51)$. Children born to families with monthly income less than Rs. 10,000 were less likely to use PS as their UIP (3.3\%), whereas families with monthly income more than Rs. 30,000 were more prone to use PS as their UIP. This shows a highly significant correlation ( $\mathrm{df}=3$, $P<0.001, \mathrm{C}=0.52$ ).

\section{Age-appropriate immunization}

Age-appropriate immunization of the study sample was assessed to compare the immunization performances of GS and PS. Table 4 shows the age-appropriate immunization rates according to UIP.

Between both age groups, the percentage of children with age-appropriate immunization was higher among PS users, but these differences were not statistically significant. Immunization coverage rates for individual vaccines were compared according to the UIP. The age composition of the two groups was significantly different. Therefore, ageadjusted immunization rates were used for this comparison [Table 5].

Coverage of almost all vaccines was same among GS and PS users except for measles, where the GS users had only a $93.77 \%$ coverage compared to the $96.87 \%$ among PS users. This difference was statistically significant.

The total contribution of the private sector for immunization of the study group according to the number of vaccine doses given was $33.6 \%$ (2544) with 95\% C.I. 29.7-37.5 [Table 2].

\section{DISCUSSION}

\section{(O)}

With the increasing involvement of the PS in the medical field over the last few decades, the contribution to child immunization by the

Table 4: Age-appropriate immunization in the study sample according to usual immunization provider

\begin{tabular}{lcccc}
\hline \multirow{2}{*}{ Age group } & \multicolumn{4}{c}{ Age appropriate immunization } \\
& \multicolumn{2}{c}{ government sector private sector } \\
\cline { 2 - 5 } & No. & $\%$ & No. & $\%$ \\
\hline $12-23$ months & $144(\mathrm{~N}=156)$ & 92.3 & $38(\mathrm{~N}=40)$ & 95.0 \\
$24-35$ m5nths & $121(\mathrm{~N}=132)$ & 91.7 & $76(\mathrm{~N}=82)$ & 92.7 \\
\hline
\end{tabular}

Table 5: Age-adjusted immunization coverage rates for EPI vaccines of the study population according to the usual immunization provider

\begin{tabular}{lccc}
\hline Age group & Vaccine & $\begin{array}{c}\text { Coverage } \\
\text { government sector }\end{array}$ \\
& & private sector \\
\hline 12-23 months & BCG & 100.0 & 100.0 \\
& OPV3 & 100.0 & 100.0 \\
& DTP3 & 100.0 & 100.0 \\
& HEPB3 & 97.80 & 97.80 \\
& Measles & 93.77 & 96.87 \\
24-35 months & OPV4 & 92.42 & 88.80 \\
& DTP4 & 92.42 & 88.80 \\
\hline
\end{tabular}

*Significant, $\chi^{2}=5.88, \mathrm{df}=1, P=0.016$ 
PS has also increased. Rising PS utilization in developing countries despite free health services available in the public sector has been attributed to the latter's inefficiency, inflexibility and lack of responsiveness to consumer demands. ${ }^{[3]}$ Although a free, accessible and a well-recognized immunization service delivery system is available in the government sector, PS involvement in immunization also keeps increasing in Sri Lanka.

\section{Private sector contribution in} immunization

The present study shows a substantial contribution from the PS for childhood immunization. For more than one-fourth of the study population, the usual immunization provider was the PS, and about one-fifth of this category exclusively used PS facilities. Altogether, $36.7 \%$ (203) of the population had used the PS at least once during the first three years of life for immunizing their children. These figures represent the highest reported contribution from the PS for immunization in Sri Lanka. The annual EPI survey of 1995 in the CMC area reported that for $19.7 \%$ of the children, the immunization provider was a general practitioner. ${ }^{[4]}$ Whilst the PS utilization has increased, immunization service utilization has shifted from general practitioners to private hospitals. The present study reported only $4.2 \%$ (23) involvement of the general practitioners, as opposed to $23.5 \%$ (130) of private hospital involvement. Most of the private hospital users received their vaccines after having consulted pediatricians. It raises the question 'whether it is for immunization or for the services of a specialist that people seek services of the PS.' The other possibility is the increasing health literacy among the general population regarding the facilities needed for vaccine quality maintenance. It has been shown in several studies that PS providers may be more responsive to patient demands. But providing immunization services through PS was often questioned due to lack of expertise and facilities in the PS to deliver high quality immunization services. ${ }^{[5-8]}$

According to the estimations done by the Pan American Health Organization through e-mail surveys, estimated PS involvement in immunization for Sri Lanka was 15\%.[9] Present study reported a total of 7,572 immunizations, out of which 2,544 (33.6\%) were carried out in the PS. In contrast, Anuradhapura, ${ }^{[10]}$ Trincomalee ${ }^{[11]}$ and Matale ${ }^{[12]}$ districts' annual immunization coverage surveys reported no involvement of PS in infant immunization. Of the surveys done outside Colombo, only the Monaragala district reported PS involvement in infant immunization, and that was only $0.7 \% .^{[13]}$

\section{Demographic and socioeconomic factors}

It was interesting to see highly significant ethnic and religious differences within the PS. Tamils had the highest percentage of PS usage, and this finding should be looked into very carefully. Further research and careful analysis of the reasons for this usage may provide valuable clues towards improving accessibility to GS services. The major problem arising from this finding concerns whether or not it is due to language barriers within the GS. If it was purely due to language barriers, the Muslim ethnic group (whose mother tongue is Tamil) also should have the same pattern of PS utilization; but the pattern was totally different among Muslims.

The present study findings regarding religious group distributions in the PS utilization are quite contrary to the study findings in India. In India the number of PS users was highest for Buddhists, followed by Christians and Sikhs. Hindus were right below in the list, just above the Islamic religious group. ${ }^{[14]}$ Lower usage of PS may be associated with general resistance to accept vaccines among Islamic religious groups, and it seems to be common in most of the countries in the region. ${ }^{[15-17]}$

The association of social class distribution, as well as monthly income of the family, with PS utilization was significant $(P<0.001)$. But the striking fact observed during the present study was the use of the PS by low socioeconomic group families. Out of all PS users, $23.5 \%$ (31) were earning less than Rs. 20,000 per month. Distribution of all PS users according to social class shows that nearly $50 \%$ of them belong to social class 3 or below. Increased use of PS in CMC area in spite of low socioeconomic status was also reported in earlier studies. The annual immunization coverage survey done by the Epidemiology unit in underserved areas of the CMC in $1999^{[18]}$ reported that $10 \%$ of all infant immunizations were done in the PS. The present study reported even higher PS usage among those lower social classes $(7 \%$ of social class 4 and $12.5 \%$ of social class 5). Not only in Sri Lanka but also in India the studies show that around $4 \%$ of the population whose standard of living is low uses the PS for childhood immunization. ${ }^{[14]}$ Reasons given for using the PS among these low socioeconomic classes was somewhat different from the higher social classes. Nearly $40 \%$ of PS users whose income was less than Rs. 10,000, used the PS purely for non-EPI vaccines. All other income categories pointed out the efficiency of the PS services as the main reason - except the highest income group, who claimed that they chose the PS because the child was born at a private hospital. The use of the PS for nonEPI vaccines among low-income groups indicates the awareness regarding new vaccines, even among the underserved population. On the other hand, parents do no consider expenses when it comes to their child's health.

\section{Age-appropriate immunization}

Age-appropriate immunization in CMC is somewhat lesser than in other parts of the country. Most recent immunization coverage survey done by Epidemiology unit reported $100 \%$ coverage for all infant vaccines in Anuradhapura district. ${ }^{[10]}$ All recent immunization coverage surveys show higher levels of immunization coverage outside the Colombo district. Further analysis of data showed that this was mainly due to low coverage of measles vaccine among both GS and PS users. Government sector users had significantly low coverage of measles vaccine. A comparison of immunization rates in India in 2002 also showed similar coverage for infant immunizations in both public and private sectors except for measles. However in that study the private sector had low (44.8\%) measles immunization coverage 
compared to the public sector (53.3\%). ${ }^{[3]}$ This is another area open for more qualitative type of study to explore reasons for low acceptance rates for measles vaccine, especially among GS users.

\section{Limitations}

Cluster sampling technique might have some impact on the study results as the study units with the same socio-demographic background are selected to a specific cluster. But this effect was minimized by using large number of small clusters. Exclusion of children who completed their infant immunization outside the CMC area may also have introduced biased estimation as this population might have low PS utilization, which may have resulted in much lower PS utilization rates, if included in the study. Selection of children more than 6 months of age might also have resulted in biased estimation of the PS utilization. There are two reasons for this probable bias. Firstly, as shown in Table 6, HiB was the most commonly used vaccine from the PS and it is used within the first 6 months. Secondly,

Table 6: Distribution of the total number of individual immunizations given by government sector and private sector

\begin{tabular}{lccccc}
\hline Vaccine & $\begin{array}{c}\text { Total in GS } \\
\text { N \% }\end{array}$ & $\begin{array}{c}\text { Total in } \\
P S ~ N \%\end{array}$ & $\begin{array}{c}\text { Total } \\
\text { doses } \\
\text { delivered }\end{array}$ \\
\hline BCG & 407 & 73.6 & 146 & 26.4 & 553 \\
DTP & 1362 & 70.4 & 572 & 29.6 & 1934 \\
OPV & 1365 & 70.3 & 576 & 29.67 & 1941 \\
Hep B & 1176 & 72.2 & 454 & 27.8 & 1630 \\
Measles & 306 & 69.6 & 134 & 30.4 & 440 \\
JE & 412 & 69.8 & 178 & 30.2 & 590 \\
HiB & 0 & 0 & 384 & 100 & 384 \\
MMR & 0 & 0 & 70 & 100 & 70 \\
VZV & 0 & 0 & 23 & 100 & 23 \\
Hep A & 0 & 0 & 7 & 100 & 7 \\
Total & 5028 & 66.4 & 2544 & 33.6 & 7572 \\
\hline
\end{tabular}

GS - Government sector, PS - Private sector in Sri Lanka, the mass media advertisement and promotion of PS vaccination were started very recently. So the percentage of children using PS may be higher among more recently born children.

\section{CONCLUSION}

According to our study we predicted that $18.8 \%$ (C.I. 15.5-22.1) of children under the age of 3 years residing in the CMC area were immunized exclusively by the PS. Another $17.9 \%$ (C.I. 14.7-21.1) of children used the PS services at least once during the first three years of life. As PS utilization is very high and expected to increase, the government should expand its immunization surveillance and services to the PS.

\section{ACKNOWLEDGMENT}

We gratefully acknowledge the contribution given by Dr. T. C. Agampodi throughout the study.

\section{REFERENCES}

1. Government of Democratic Socialist Republic of Sri Lanka, Progress Report to the Global Alliance for Vaccines and Immunization (GAVI) and The vaccine Fund 2004.

2. Ashraf $\mathrm{H}$. Public and private bodies unite to push for global immunization. Lancet 2000;355:477.

3. Howard DH, Roy K. Private care and public health: Do vaccination and prenatal care rates differ between users of private versus public sector care in India? Health Serv Res 2004;39:2013-26.

4. Epidemiological Unit. EPI Coverage survey-urban and rural comparison of CMC and Monaragala. Weekly Epidemiological Report 1995;23:1-3.

5. Brugha R, Zwi A. Improving the quality of private sector delivery of public health services:
Challenges and strategies. Health Policy Plan 1998;13:107-20.

6. McPake B. The role of the private sector in health service provision. In private health providers in developing countries: Serving the public interest Bennett S, McPake B, Mills A, editors. Zed Books: London; 1997. p. 21-39.

7. Mills A, Brugha R, Hanson K, McPake B. What can be done about the private health sector in lowincome countries? World Hosp Health Serv 2002;38:24-30,41-4.

8. Newell J. The implications for TB control of the growth in numbers of private practitioners in development countries. Bull World Health Organ 2002;80:836-7.

9. Pan American Health Organization, Role of the for profit private sector. EPI Newsletter: 1996. XVIII (6).

10. Epidemiological Unit, EPI Coverage survey-2004 Anuradhapura district. Weekly Epidemiological Report 2005;32:1-3.

11. Epidemiological Unit, EPI Coverage survey-2003 Trincomalee district. Weekly Epidemiological Report 2004;31:1-3.
12. Epidemiological Unit, EPI Coverage survey-1997 Matale survey. Weekly Epidemiological Report 1997;25:1-3.

13. Epidemiological Unit, EPI Coverage assessment and Measles morbidity and mortality surve DPDHS division Monaragala. Weekly Epidemiological Report 1995;23:1-3.

14. Walsh, J. How large is the role of the private secto in immunization. Bay Area International Group (BIG). 2002.

15. Available from: http://www.gaviftf.info/forum/ppt/ jwalsh.ppt.

16. Dalal A, Silveira MP. Immunization Status of Children in Goa. Indian Pediatr 2005;42:401-2.

17. Thacker N, Shendurnikar N. Current status of polio eradication and future prospects. Indian J Pediat 2004;71:241-5

18. Epidemiological Unit, Immunization and vaccine preventable disease survey- underserved areas of Colombo Municipal Council. Weekly Epidemiological Report 1999;27:1-3.

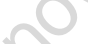

Source of Support: Nil, Conflict of Interest: None declared.

\section{Author Help: Choosing an appropriate category of article for faster publication}

The manuscript system (www.journalonweb.com) allows the authors to check a likely publication date for a newly submitted article. Based on number of articles in review, number of accepted articles and acceptance rate, the system estimates the likely publication date for an article submitted on a given date.

If there are too many articles in a category e.g., case report, a newly submitted case report if accepted may have to wait for a long period before publication. Hence, the author can check other categories e.g. letter to editor or images, for such paper and submit to another category of articles. 